\title{
JAIME II Y LA «CONSTITUCIÓN» DE LA CORONA DE ARAGÓN
}

\author{
José María DE FRANCISCO OLMOS \\ Universidad Complutense de Madrid
}

Durante mucho tiempo, la figura de Jaime II en sus aspectos constitucionales ha sido ensombrecida por la de su nieto, Pedro IV el Ceremonioso, al que tradicionalmente se atribuyen muchas de las modificaciones constitucionales que en realidad pertenecen por derecho a Jaime II. Veremos brevemente como el rey acepta y consolida el «pacto» con el reino que se realiza mediante las ceremonias de coronación, como se intentará mitificar la figura del rey y la dinastía, y por fin la manera de asegurar la sucesión y consolidar la figura del primogénito dentro de la administración de la Corona, hecho trascendental en el que nos detendremos con mayor amplitud.

\section{LA CORONACIÓN Y SUS CEREMONIAS}

- El uso del título real de Aragón. Jaime II no usó el título de rey hasta después de tomar posesión del reino y jurar sus fueros, cosa que hizo durante las cortes de Zaragoza (1291), aunque sin ser solemnemente coronado ya que Jaime ya había sido ungido rey de Sicilia, y no consideró oportuno repetir las ceremonias'.

No hay duda de que Jaime quería evitar los problemas que había tenido Alfonso III por titularse rey antes de las ceremonias de toma de posesión y jura, a lo que había

1 Jaime II no fue coronado en Aragón, ya que anteriormente había sido ungido y coronado como rey de Sicilia. El hecho de no repetir las ceremonias se debió a dos razones: una que la unción no es reiterable, dado su carácter es en sí irrepetible; por otra parte las ceremonias de la coronación en Aragón estaban muy mediatizadas por su especial relación con la Santa Sede, ya que el reino era feudatario del Papado y en esos momentos las relaciones de Jaime II con Roma eran extremadamente tirantes, a lo que hay que añadir que al haber depuesto los papas a los reyes de la Casa de Barcelona tras la invasión de Sicilia la coronación podría haberse considerado una provocación. 
que añadir que la Santa Sede había privado de sus estados y título a Pedro III y sus sucesores, por lo que Jaime II decidió actuar en este tema con el mayor de los cuidados, partiendo de la base de que su «honor» personal quedaba a salvo ya que a todos los efectos podía usar el título real de Sicilia.

- El derecho de sucesión y la integridad de la herencia. Asimismo Jaime II declaró recibir la Corona no por el testamento de su hermano, sino por derecho sucesorio, rechazando la política de particiones ${ }^{2}$. Un objetivo que llevará a sus últimas consecuencias en 1319, durante las cortes de Tarragona, al aprobar en ellas el llamado Privilegio de Unión, por el cual se consagraba la indivisibilidad de la Corona de Aragón, desde entonces el rey debía jurar mantener la unidad y si faltaba a su juramento los estados podían resistirle por la fuerza. Este juramento de indivisibilidad será prestado el día de la coronación del monarca, formando parte del conjunto de promesas solemnes del soberano ante los representantes de la Corona ${ }^{3}$.

- Las protestaciones. Igual que hacían sus antepasados desde la época de Pedro III el rey realizó una protesta formal, afirmando que «no recibía la corona con reconocimiento que por el reino debiese hacer a la Sede Apostólica, conservando su derecho cuanto a ser libre y exempto, como lo había sido y lo era en lo temporal ${ }^{4}$. Con este acto de nuevo Jaime II intenta mostrar sus independencia respecto de otros poderes, en este caso el Papado.

- El juramento. Al no coronarse nuevamente Jaime II no tiene que enfrentarse al problema de si el juramento de los fueros debía hacerse antes o después de la coronación; lo que sí sabemos es que el rey realizó el juramento como primer acto de las Cortes de Zaragoza, como ya mencionamos. Este acto institucional era importantísimo e ineludible, simbolizando la continuidad y vigencia de las ideas contractuales entre el rey y el reino ${ }^{5}$. Y Jaime II entenderá este juramento no como una cortapisa a su poder

2 Alfonso III en su testamento (10-III-1287) dejó como heredero de la Corona a su hermano Jaime, siempre y cuando abandonara el trono siciliano, en caso contrario debía sucederle su otro hermano, Federico. Jaime no aceptó este testamento y tras presentarse en Barcelona reclamó el trono por derecho de primogenitura y en virtud del testamento de Pedro III (3-VI-1282), que le nombraba heredero en caso de morir el primogénito Alfonso. Esta protesta y declaración de derechos la volvió a realizar ante las Cortes de Zaragoza cuando juró los fueros (Jerónimo ZURITA, Anales de la Corona de Aragón. Zaragoza, 1592, libro IV, capítulos CXXII y CXXIII. Edición de Ángel CANELLAS, Zaragoza 1970, tomo II, pp. 416-422).

3 Bonifacio PALACIOS, La Coronación de los Reyes de Aragón 1204-1410, Valencia, 1975, pp. 188-193.

4 Este texto recogido de J. BLANCAS, Coronaciones de los serenísimos reyes de Aragón, con dos tratados del modo de celebrar Cortes, Zaragoza, 1641, p. 25; es el único testimonio que nos habla de este acto, ya que no' se conserva el documento notarial que el rey debió hacer para que se oficializase su protesta, como lo hicieron antes de él Pedro III y Alfonso III, cuyas actas notariales sí se conservan.

5 De nuevo hay que esperar al reinado de Pedro IV para que la costumbre se convierta en ley, siendo sancionada por el rey en las Cortes de Zaragoza de 1348. De ese momento el Privilegio General y su Declaración por Jaime Il pasan a formar parte integrante del Fuero de Aragón. Ver P. SAVALL y S. PENEN, Fueros, observancias y actos de Corte del reino de Aragón, Zaragoza, 1866 (reedición Zaragoza 1991), tomo I, pp. 21, 25 y 26. 
sino como una nueva arma para luchar contra los que intenten reducir su campo de acción, como lo veremos en el siguiente apartado.

\section{EL MITO DE LOS FUEROS Y EL MITO DEL REY}

Jaime II decide aceptar "los fueros" como base de su actuación interior en la Corona, no luchar contra ellos, de esta manera se convierte en principal defensor de éstos, arrebatando a los nobles la bandera del foralismo; y desde esta perspectiva pudo reducir mejor a la nobleza (altercados de 1301 y 1325 especialmente) y a las ciudades cuando sus pretensiones eran excesivas.

Ahora es el rey quien acude a las Cortes y al Justicia para reclamar el cumplimiento de los fueros contra las exigencias de los nobles, y consigue sus objetivos, las sentencias del Justicia se convierten en inapelables. Los fueros se convierten así en la primera fuente legal de la Corona, a la que tanto el rey como los súbditos deben someterse, alcanzando la categoría de mito, en tanto en cuanto aparece en la conciencia general la teoría de que en Aragón antes fueron los fueros y después el rey, y que éste sólo lo era verdaderamente cuando los juraba, pudiendo ser depuestos si los incumplían ${ }^{6}$.

Inmediatamente el rey se lanzaría a consolidar, como contrapeso de lo anterior, el mito del rey, sacralizando su persona y actos, y en general cuanto le rodea para elevarse por encima de sus súbditos sublimando su majestad con el fin de robustecer su poder y autoridad, mediatizados precisamente por el juramento que se ha visto obligado a hacer antes de tomar posesión de sus estados. Paradójicamente, en la base del nacimiento del mito regio está el prestigio que la monarquía obtiene ante el pueblo al arrebatar a una nobleza egoísta la bandera de los fueros y de la legalidad?

\section{EL PRIMOGÉNITO Y LA SUCESIÓN}

La Figura del Primogénito va a ser uno de las más beneficiadas por la política de Jaime II, que asegurará la adscripción a su figura de la gobernación general, e incluso impondrá el derecho de representación.

- Se consolida el «juramento del primogénito» con unas características formales que venían estructuradas desde 1228. El acto es normalmente preceptuado por el rey, siendo prestado por «todo el reino", es decir, barones, caballeros, representantes de las ciudades y demás municipios. Es habitual la ausencia de los eclesiásticos. En to-

6 En estos momentos surge la idea de adoptar un emblema para representar al reino, se elabora un escudo del reino de Sobrarbe, unido a la leyenda del origen de los Fueros y del Justicia de Aragón, se recuperará la legendaria cruz de Íñigo Arista, y la cruz de San Jorge con cuatro cabezas de moros que recordaban la gran batalla de Alcoraz y la conquista de Huesca, uniendo todos estos símbolos a los palos rojos de la dinastía catalana. Se formó así el escudo del reino. Ver J.A. SESMA MUÑOZ, “El sentimiento nacionalista en la Corona de Aragón y el nacimiento de la España moderna”, en Realidad e Imágenes del poder (Coordina Adeline Rucquoi), Valladolid, 1988, p. 226.

7 B. PALACIOS, La Coronación..., ob. cit., pp. 196-200. 
dos los casos el rey ordena que los súbditos presten juramento de fidelidad y homenaje por este orden. El vínculo que estos actos crean entre el futuro rey y el pueblo que los presta no es ciertamente el del vasallaje feudal propiamente dicho, que, como se sabe, llevaba la contrapartida de una recompensa y era, además, soluble a la voluntad del vasallo. Precisamente esto era lo que se trataba de evitar, se buscaba consolidar el reconocimiento por los súbditos del vínculo que el día de la sucesión uniría naturalmente a éstos con su «señor natural», el rey. Era una promesa de cara al futuro, que unas veces incluía los compromisos propios de la fidelidad jurada (1228) y otras no (1257). Queda claro así que lo esencial del acto no son los compromisos de fidelidad, sino garantizar en todo cuanto fuera posible la promesa de reconocer al sucesor. De ahí también que, al revés de lo que ocurre en el vasallaje propiamente dicho, el homenaje siga al juramento, tanto si éste incluye lo relativo a la fidelidad como si solamente contiene la promesa de aceptación del sucesor como rey en el futuro. En este último caso la naturaleza del homenaje no ofrece dudas.

En cuanto al juramento en sí se usó siempre (excepto en el caso de Valencia al infante Alfonso en 1257) la fórmula de «fidelidad jurada» que se usaba comúnmente en Occidente para consolidar el homenaje y el vasallaje feudal. Tal vez el papel instrumental, de refuerzo, que dicha fórmula desempeñaba en su utilización original facilitó la adaptación de la misma a otros usos, como el de reforzar el reconocimiento del sucesor.

En cuanto a sus efectos jurídicos, hay que ponerlos en relación con su eficacia coercitiva en la medida en que el juramento y el homenaje eran una garantía contemplada y regulada por la ley ${ }^{8}$.

- La procuración general y su adscripción al heredero. Tras su llegada al trono y el nacimiento de sus hijos varones, Jaime II hace que su primogénito D. Jaime (nacido en 1296) fuera jurado como primogénito en las Cortes de Zaragoza de 1301, y al año siguiente (con apenas seis) fue nombrado procurador general en Aragón y Cataluña. Era la primera vez que este cargo se asignaba a un menor, con la trascendencia que ello conllevaba, ya que dejaba claro la intención de unir este oficio a la condición de primogénito de la Corona. Obviamente el infante no pudo ejercer sus funciones, porque lo que su padre nombró varios "gerens vices" para que actuaran en su nombre ${ }^{9}$. En 1309 el rey nombra a su hijo como procurador general de Valencia ${ }^{10}$, con lo que el infante consigue ya la procuración general de la Corona. El que un cargo tan importante haya sido conferido al primogénito siendo un menor implica que el rey no ha buscado las cualidades de la persona para regir la administración, sino solamente las

8 En el de 1228 se dice que el homenaje era de manos y de boca. Ver Bonifacio PALACIOS, «La práctica del juramento y el desarrollo constitucional aragonés hasta Jaime I", en Cuadernos de Historia Medieval, 1, UAM, Madrid, 1979, pp. 36-39.

9 Tales como Bernardo de Fonollar para Cataluña (ACA, AR. Reg. 231, fol. 19) y Arnaldo de Luna para Aragón (ACA, AR. Reg. 231, fol. 12v.).

10 Ya que lo manifiesta explícitamente en el exordio correspondiente al nombramiento de Artal de Orta como su "gerens vices" en dicho reino (ACA, AR. Reg. 232, fol. 319). 
condiciones concurrentes en él independientes de toda idoneidad, que no puede ser sino la primogenitura, y eso revela una intención manifiesta de adscripción ${ }^{11}$.

El infante, al alcanzar la mayoría de edad, juró, ante las cortes de Zaragoza (19 de mayo de 1311), guardar los fueros, privilegios y libertades del reino, aprobando y ratificando la confirmación del privilegio general que el rey su padre había concedido y los otros privilegios ${ }^{12}$.

Tras hacer esto, pudo entrar en la plena posesión de la procuración, que gestionó con notable éxito si hemos de creer las cartas que su padre le envió felicitándole ${ }^{13}$, gracias principalmente a sus buenos consejeros, tales como Bernardo de Fenollar (su mayordomo y lugarteniente en el cargo), Artaldo de Alagón (su senyalero, alférez, desde 1312), Gonzalo García, Esteban de Roda, Pedro de Pomar, Blas Maça de Vergua, Pero Sánchez de Calatayud y otros.

Pero su actuación, a partir de 1318, se volvió excesivamente rigurosa (tal vez por el empeoramiento de su estado físico), lo que llevó a Jaime II a desautorizarle en varias ocasiones, aunque sin apartarle del cargo, e incluso encomendándole importantes asuntos, tales como la resolución de uñ conflicto entre la ciudad de Valencia y don Artaldo de Luna, que el rey no podía atender por estar negociando las «cosas» de Sicilia ${ }^{14}$.

El comportamiento del infante era cada vez más extraño, a veces desaparecía durante días retirándose a lugares solitarios (actitud que le reprochaba el rey como impropia de un heredero con graves responsabilidades en el gobierno de la Corona), esquivaba el trato con el rey (incluso durante una grave enfermedad de éste) y la celebración de su boda (concertada con Leonor de Castilla desde hacía tiempo). Todo esto llevó al rey a escribir al papa, y éste envió una larga carta al infante aconsejándole abandonar sus malos hábitos de forma cordial ${ }^{15}$.

Nada se arregló, y el tiempo transcurría, se prepararon los esponsales, que tuvieron lugar el 18 de octubre ${ }^{16}$, y ese mismo día el infante desapareció de la corte. Finalmente el 22 de diciembre de 1319 renunció formalmente a todos sus derechos de primogenitura, como le exigió el rey, tomando el hábito de la orden de San Juan del Hospital ${ }^{17}$.

11 Jesús LALINDE ABADÍA, La Gobernación General en la Corona de Aragón. Madrid-Zaragoza, 1963, p. 52.

12 J. ZURITA, Anales..., Libro V, capítulo 90 (tomo II, p. 742).

13 ACA, Reg. 337, tol. 328v. (Poblet, 23 de junio de 1313).

14 ACA, Reg. 244, fol. 317. (Barcelona, 3 de julio de 1318).

15 Colección de bulas papales, Leg. 30. Juan XXII, n 33. Avignon, 19 de agosto de 1319, publicada por J.E. MARTÍNEZ FERRANDO, Jaime // de Aragón, Barcelona, 1948, tomo II, n² 292, pp. 213-214.

16 Unos días después, el 22, Jaime II envió una larga carta a la reina de Castilla, doña María de Molina, explicando la extraña conducta del infante y todas las quejas que tenía contra él que muestra, mejor que ningún relato, las esperanzas defraudadas de Jaime II. ACA, Reg. 245, fol. 198v., publicada por J.E. MARTÍNEZ FERRANDO, ob. cit., tomo II, no 299, pp. 220-221.

17 Jaime II había intentado por todos los medios evitar esta decisión, como consta en los documentos notariales que dan fe de la renuncia del primogénito (ACA, Reg. 348, fol. 22v, Pergaminos de Jaime II, $n^{\circ}$ 3754) y en los de su ingreso en los sanjuanistas (ACA, Reg. 348, fol. 24, Pergaminos de Jaime II, $\mathrm{n}^{\circ}$ 3755). 
Jaime II insistió en que su hijo optara por la orden de San Juan, ya que aquellos que vestían su hábito eran considerados profesos en el mismo día de recibirlo y, por lo tanto, no podían volverse atrás de su decisión. El rey no quería más vacilaciones ni problemas $^{18}$.

Inmediatamente, el monarca convocó cortes generales, donde fueron leidos los documentos notariales antes mencionados, siendo declarado primogénito y heredero del trono el infante don Alfonso, conde de Urgel ${ }^{19}$, segundogénito del rey. Don Alfonso fue nombrado inmediatamente (de hecho en el mismo mes de diciembre) Procurador general, cargo que antes tenía su hermano, ya que como nuevo heredero «ut segundogenito ad primogenitura sui germani predicta subrogato, suplebit in omnibus officium regiminis regnorum ${ }^{20}$. También se ampliaron notablemente sus dotaciones territoriales ${ }^{21}$.

D. Alfonso cumplió sus funciones de forma muy grata a su padre, como éste lo expresa en una carta al tesorero real, Pedro March, felicitándose por la manera en que don Alfonso había llevado el proceso abierto contra Ramón Folch, vizconde de Cardona ${ }^{22}$. Tanto es así que en 1321 el rey amplia notablemente sus poderes al permitirle ejercer plenamente su oficio y terminar completamente los negocios que trate en apelación, aún cuando el rey esté presente ${ }^{23}$. En 1323 el infante recibe facultad

J. ZURITA, Anales..., libro VI, capítulo XXXII (tomo III, pp. 117-122), dedica varias páginas a contar con detalle los hechos narrados anteriormente.

18 De hecho los primeros meses tras su profesión el ahora venerable fray Jaime mostró extrañas actitudes, e incluso pareció querer recuperar su posición en la Corona. Poco después cambió el hábito sanjuanista por el de la orden de Montesa, pasando a residir en Santes Creus (1320). Su vida fue luego bastante azarosa, en 1323 se encuentra en Valencia «en malas compañías», lo que lleva al rey a ordenar a su hijo Pedro, conde de Ribagorza, que se llevara a Jaime, de buen grado o por la fuerza, de la ciudad, siendo posteriormente retenido en Santes Creus de manera permanente, falleciendo en julio de 1334.

19 Alfonso era conde de Urgel y vizconde de Ager desde su matrimonio con Teresa de Entenza en 1314, cumpliendo así el testamento del conde Ermengol de Urgel, que dispuso la boda de su hija con Alfonso y la venta de sus estados al rey por 100.000 libras jaquesas.

20 Carta de Jaime 11 al rey de Mallorca informándole de la renuncia de su primogénito. ACA, AR. Reg. 348 , fol. 40 . «el segundogénito, subrogado en la primogenitura de su hermano, le suplió totalmente en el oficio del gobierno de los reinos".

También reconoce este hecho el mismo Pedro IV, en la «Crónica de Pere el Ceremoniós» libro I, cap. XLII (p. 1017 de la Ed. de F. SOLDEVILA en Els Quatre Grans Cròniques).

21 Además de Urgel y Ager, el infante tenía los castillos de Perrúa, Gual, Fels y la tenencia de la castellanía de Benabarre (ACA, Reg. 25, fol. 277r.); así como la baronía de Josa y la tierra de Lavança, con los castillos de Josa, Fornols, Ossera, Esplugas de Lavança, Ciscar, Pardina, Cornellana y Montergull. A los que se añadió el castilla y villa de Albalate de Cinca en 1318 (A. SINUES y A. UBIETO, El patrimonio real en Aragón durante la Edad Media, Zaragoza, 1986, documento 53, p. 35), y sobre todo el castillo y villa de Luna en 1320 (ACA, Pergaminos de Jaime II, $n=3828$ ). Dato citado por J. ZURITA, Anales..., libro VI, capítulo XXXVI (tomo III, pp. 133-134).

22 ACA, Reg. 339, fol. 373 (Valencia, 10 de abril de 1321).

23 ACA, AR. Reg. 233, fol. 23v. Texto publicado por J. LALINDE, ob. cit, documento XXIV, pp. 517-518. 
plena para destituir y nombrar a sus «gerentes vices», que hasta entonces eran nombrados directamente por el rey, mientras ahora el monarca simplemente se reserva el «placet». Así, a finales del reinado de Jaime II, el prímogénito, como Procurador General, ha extendido su poder a todos los territorios de la Corona (incluida Cerdeña) y ha conseguido controlar a todos los oficiales que dependen de él, creándose una posición de privilegio en la Corona a la que sólo le falta la asignación explícita por ley del cargo al primogénito ${ }^{24}$.

Puede decirse que el sistema de la procuración general es el resultado de la convergencia de dos líneas, que son la tendencia a la centralización administrativa y la inclinación natural de los reyes a asegurar la sucesión, promocionando al primogénito mediante su inserción en la cúspide de la administración pública.

- El derecho de representación. El derecho de representación en Aragón fue reconocido en la mayoría de los testamentos reales, pero no se plantea el problema como tal hasta el reinado de Jaime $\mathrm{l}$, cuando el rey promete $(20-\mathrm{X} \mid-1275)$ a su primogénito el infante Pedro que hará jurar al hijo de éste, Alfonso, como heredero del heredero ${ }^{25}$.

Tanto el rey Jaime I como don Pedro, deseando evitar los problemas sucesorios que se estaban desarrollando en Castilla, decidieron promover la jura de Alfonso (primogénito de don Pedro, nacido en 1265) como heredero del trono ante la inminente partida de Don Pedro a Castilla con refuerzos para frenar la invasión musulmana. Era el juramento del primogénito del primogénito, primera muestra de la aceptación «institucional» del derecho de representación en Aragón y de la posición de fuerza que en estos momentos tenía el infante en la Corona. De este modo, a instancias de su hijo, el rey Jaime en un documento de 19-XI-1275 daba poder al infante para que, si moría antes que él, dejase los reinos de Argón y Valencia y el condado de Barcelona a su primogénito Alfonso y a sus otros hijos en defecto de aquél. Igualmente, el rey se comprometía a observar y hacer observar en todo esta disposición, de manera que, una vez muerto él, los reinos pasasen al heredero designado por el infante ${ }^{26}$. Partien-

24 Este último paso se dará en 1366, cuando en las Cortes de Calatayud se promulgue el Fuero «Statuimus», según el cual se dispone que el Primogénito del Rey pueda regir el oficio de la Gobernación o Procuración General, y usar y ejercer la jurisdicción civil y criminal del mismo después que tuviere 14 años y jurara respetar los fueros.

Esta ley enfrentaría a Pedro IV con su heredero Juan en 1386; en esos momentos ambos se encontraban enfrentados por motivos personales y su distinta orientación política, por lo que el rey quiso despojar a su hijo de la Gobernación General. El Duque Juan se opuso y firmó de derecho ante el justicia de Aragón contra su padre, y le fue recibida la «iurisfirma». El Fuero de 1366 lo dejaba claro, el Primogénito era Gobernador General tras cumplir 14 años y jurar respetar los fueros, y lo era por la Ley; no por designación del Rey, que no podía destituirle de un cargo que no le había dado, sino que lo tenía por derecho.

25 El documento regio está en ACA, Pergaminos de Jaime I, no 2253, y en Reg. 20, fol. 300v. Publicado por CODOIN-ACA, VI, documento LIII; Ver B. PALACIOS MARTÍN, «La práctica del juramento...", ob. cit., pp. 35-36.

26 ACA, Reg. 20, fol. 300v. Publicado por Ferrán SOLDEVILA, Pere el Gran. L'Infant, Barcelona, Institut d'Estudis Catalans, Memories de la Secció Històrico Arqueològica, XI, 1950. Apéndice, documento 55, pp. 472-473. 
do de esta situación de reconocimiento de derechos del infante Pedro, el rey Jaime emitió el documento antes comentado del 20-XI, donde prometía al infante que antes de que éste partiera en servicio de Dios para ayudar a Castilla, haría jurar y hacer homenaje por sus reinos a su hijo mayor, el infante Alfonso, para que lo tuvieran por rey y señor después de la muerte de ambos ${ }^{27}$. Este documento fue una simple declaración de intenciones, ya que dicha jura no se realizó, al no partir inmediatamente el infante con las tropas preparadas para apoyar a los castellanos, pero el precedente estaba claro.

Cincuenta años después tuvo lugar la institucionalización de este hecho. Durante la campaña sarda dirigida por el primogénito de Jaime II, D. Alfonso, ocupó de forma interina el cargo de procurador general su hermano, el infante Pedro, pues bien en esos momentos pidió al rey ser declarado infante heredero, alegando la posibilidad de que su hermano muriera en Cerdeña, la corta edad del hijo de éste (el futuro Pedro el Ceremonioso), y la mala salud del propio Jaime II.

Don Pedro, era el hijo preferido del rey, tenía un nutrido grupo de simpatizantes entre la corte y la nobleza, disponía de cuantiosas rentas (había recibido el condado de Ribagorza en 1322) y había mostrado sus cualidades de gobierno en la procuración. Jaime II dudó durante algún tiempo, pero tras la vuelta de don Alfonso, el rey convocó Cortes en Zaragoza (1325) y ordenó jurar como heredero de sus reinos, en casó de morir el primogénito, al futuro Pedro el Ceremonioso primogénito de éste ${ }^{28}$, es el llamado juramento del primogénito del primogénito. Se consolidaba así el derecho de representación en Aragón, que por primera vez se había esbozado en 1275 por Jaime I. Aunque no sin la protesta del conde Pedro de Ribagorza, hijo menor del rey. Poco después, en su testamento de 1327 Jaime II reconoce explícitamente el derecho de representación, aunque sólo en favor de su primogénito Alfonso y de sus descendientes varones; en defecto de estos, sucede su segundogénito, a cuyos descendientes no se les reconocen el derecho de representación, pasando el orden sucesorio al tercer hijo de Jaime II.

\section{CONCLUSIÓN}

Con todas estas medidas Jaime II buscó la consolidación definitiva de la Corona de Aragón, su indisolubilidad, una sucesión pacífica y reglada (derecho de representación y adscripción de la procuración general al primogénito consiguiendo que lo que hasta entonces era una simple entrega de poderes coyunturales se transforme en derecho consuetudinario y en parte de la administración cotidiana de la Corona) así

27 ACA, Reg. 20, fol. 300v. 20 de noviembre de 1275. A. BALLESTEROS, Alfonso $X$ el Sabio, Madrid-Barcelona 1964, p. 776; B. PALACIOS, «El juramento...», ob. cit., p. 35.

28 J. ZURITA, Anales..., libro VI, cap. LXII (tomo III, pp. 230-231) y «Crónica de Pere el Ceremoniós», libro I, cap. XLII. El documento completo del juramento (15 de septiembre) lo publica D. GIRONA I LLAGOSTERA, «Itinerari de l'infant Pere (1319-1336)», en Estudis Universitaris Catalans, 18 (1933), pp. 346-350. 
como una delimitación clara del "pacto» entre el rey y el reino que se formaliza en los actos de coronación, reforzando los poderes del monarca alentando el mito del rey.

En este período se dan los pasos necesarios para consolidar de manera definitiva la figura del heredero dentro del organigrama "constitucional» de la Corona de Aragón, entregándole unos poderes, en razón de su posición en la sucesión al trono, que le colocan en una posición inigualable dentro de la Corona, y con una capacidad de maniobra que no tienen ninguno de los herederos de los reinos de la Europa Occidental.

Ahora bien, esta entrega de poderes que consolida y fortalece la figura del heredero convirtiéndole en el principal colaborador del rey conlleva también sus problemas: en primer lugar la asignación de este importante oficio cuando el rey no tiene un hijo varón ${ }^{29}$, y en segundo la posible confrontación de políticas entre el rey y el heredero que podría desembocar en un conflicto de grandes dimensiones ${ }^{30}$.

En cualquier caso desde este momento se potencia esta figura, y seguirá en ascenso, salvo algún breve período, hasta el reinado de Juan II, cuando su hijo y heredero Fernando el Católico se convierte en su principal colaborador y prácticamente co-regente, para luego vaciarse de contenido en el reinado de los Reyes Católicos.

29 Hay que recordar los años en que Pedro IV tuvo como única posible heredera a su hija Constanza, y los esfuerzos que hizo entonces por modificar la Procuración; y también el problema que se planteó durante el reinado de Martín I, ya que la asignación de la Gobernación General podía significar en sí misma la designación del heredero al trono en un momento en que había varios candidatos a él.

30 Ya hemos comentado brevemente el enfrentamiento de 1386 entre Pedro IV y el Duque Juan; pero más importante fue el de Juan II con Carlos de Viana, que nunca fue Gobernador General al no cumplir el requisito de jurar los fueros, ya que el rey lo evitó al no convocar Cortes para realizar el acto; lo que fue un motivo más de enfrentamiento entre ambos. 